\title{
The Need for Fixed Dose Combination (FDC) for the Management of Type 2 Diabetes in Mauritius
}

\author{
Mohammad Yaasir Ozeer ${ }^{1}$, Manish Putteeraj ${ }^{* 2}$ and Jhoti Somanah Bhugowandeen ${ }^{2}$ \\ ${ }^{1}$ Diabetes and Vascular Health Centre, Souillac Hospital, Savanne Road, Souillac, Mauritius \\ ${ }^{2}$ School of Health Sciences (SHS), University of Technology, Mauritius, LaTour Koenig. Pointe-aux-Sables, Mauritius
}

${ }^{\star}$ Corresponding Author: Dr. Manish Putteeraj (PhD), School of Health Sciences, University of Technology, Mauritius, La Tour Koenig, Pointe-aux-Sables, Republic of Mauritius; Tel: +2302075250, +23058542264; E-mail: mputteeraj@umail.utm.ac.mu

Received: March 03, 2019; Accepted: March 11, 2019; Published: March 25, 2019;

\begin{abstract}
The State health services of Mauritius are provided free to all 1.27 million inhabitants of the island. Despite so, successive surveys by the Ministry of Health and Quality of Life have shown that diabetes remains a major public health threat to Mauritians. With $24 \%$ of the adult population affected by (type 2 diabetes) T2D, our island is ranked amongst those countries with highest diabetes-related mortality, which emphasizes the need for educating the population proper self-management of the disease. It is also evident that poor treatment adherence looms large. Patients with T2D under conventional treatment often require multiple medications to achieve glycaemic control. This induces a significant pill burden when coupled with co-morbid conditions associated to diabetes and deters adherence to treatment. Public health institutions in Mauritius support the usage of loose pills for diabetes treatment as opposed to private institutions who promote the adoption of Fixed Dose Combination (FDC) therapy as a means to improve treatment efficacy. A scaled-study was conducted to explore the efficiency and patients' perspectives on FDC in the management of T2D. 65 patients from the Diabetes and Vascular Health Centre were grouped according to their treatment regimen: FDC from start; switched to FDC from loose pills; reverted to loose pills after trying FDC and loose pills treatment. Patients were interviewed and their clinical parameters recorded. Results showed that $67.7 \%$ of patients were taking more than 7 pills a day to achieve glycaemic control, with only $30.8 \%$ being made aware of possible FDC options by their healthcare practitioner. $96.3 \%$ patients who were on loose pills expressed their willingness to shift to FDC if made available in public institutions. Overall glycaemic control was better managed among the FDC group. Our findings concluded that the loose pill regime was indeed problematic for diabetics to achieve optimal glycaemic control. FDC could be pivotal in improving their health outcomes, barriers such as communication of treatment availabilities, financial constraints, shared decision-making and self-management training also need to be addressed.
\end{abstract}

Keywords: Fixed dose combination (FDC), type 2 diabetes mellitus (T2DM), glycaemic control, diabetes management, conventional treatment, pill burden

\section{Introduction}

Diabetes is one of many leading chronic diseases plaguing countries around the world. Commonly considered as a complex heterogenous disease that is associated to the onset of a number of life-threatening secondary complications such as cataract, chronic renal failure, cardiovascular diseases and neurovascular-related amputations- this disease has catastrophic impacts on the quality of life of individuals with uncontrolled diabetes [1]. According to the International Diabetes Federation (IDF), 425 million people suffer from diabetes worldwide. The island of Mauritius is ranked highest in the region of South East Asia with an estimated 1 in every 4 Mauritian adults diagnosed with diabetes, representing a staggering prevalence rate of $24 \%$ [2]. Despite being preventable, type 2 diabetes mellitus (T2DM) accounts for the vast majority of cases. The numerous pathways altered by the onset of T2DM partly justifies the multiple therapeutic agents required over time for to achieve glycaemic control. Indicators such as Fasting Blood Sugar (FBS) levels capped at $7.8 \mathrm{mmol} / \mathrm{L}$ and glycosylated haemoglobin levels (HbA1C) of less than $7.0 \%$ are representative of effective treatment and proper glycaemic control [3]. The natural history of T2DM, being a progressive condition, precipitates a shift towards an intensification of medications with time to alleviate the pancreatic stress induced to sustain a normal glycaemic index; as well as other co-morbidities leading to the initiation of polytherapy thereby increasing the complexity of medication [4]. Multifactorial medications for diabetes and related co-morbid conditions can involve up to 10 tablets or more per day, ultimately leading to pill burden over time [5].

Despite T2DM being a progressive disease, patients can still live long, high quality lives by properly managing the disease. At the root, core management of T2DM includes healthy diet, exercise regimen and correct use of medications as prescribed by a physician. However, extent of adherence to treatment has a profound effect on glycaemic control. Behaviours related to treatment adherence and compliance are essential recommendations, where adherence can be measured as the proportion of patients taking $\geq 80 \%$ of their prescribed medications [6]. It is also agreed to be elemental in lowering the risks of microvascular and macrovascular complications and mitigating or delaying at most the onset of polypharmacy [7].

Poor adherence is reflected in various ways including noninitiation of therapy, self-reduction of prescribed medication dosage, 
non-completion of the medication course among others [8]. On a global scale, poor adherence is shown to impact more than $50 \%$ patients, translating to increased morbidity rates, financial burdens and polypharmacy $[9,10]$. This can be further supported by systemic reviews which report significant declines in the mean dose-taking compliance when number of daily doses increase [11, 12]. Aside from the profound effect of complexity of treatment on adherence, there do exist several other factors that act as co-determinant in the precipitation of poor adherence. Psychological factors inclusive of poor social support and mental health, health literacy status and general attitude towards effectiveness of treatments based on past experiences from other therapeutic interventions may act as mediators of poor adherence [13]. Those factors related to the healthcare system, such as consultation timing limitations, patient-physician interaction and provision of care by multiple physicians among others should not be dismissed [14].

The impacts of poor adherence are extensive, such as medical readmissions [15] and the onset of clinical inertia; a detrimental behavioural characteristic exhibited by a proportion of healthcare professionals, which is also prevalent in T2DM patients with poor adherence $[16,17,18]$. It should be fair to mention that patients with suboptimal health literacy and less engaged towards treatment practices are affected by delays in treatment escalation, consequential effect of physician-mediated clinical inertia [19]. The most obvious and effective remedial actions to address poor adherence primarily revolve around decreasing polypharmacy to simplify medication regimen and pill burden [11]. As such, the development of dual therapies in the form of loose-pill combination therapy or fixed-dose combination (FDC) therapy has proved to be quite effective in promoting adherence in T2DM patients. Patients who either switched from coadministered dual therapy to FDC or from glyburide or metformin monotherapy to FDC were more adherent to [20,21]. This therapeutic alternative has also showed promising results in helping newly diagnosed T2DM patients in achieving optimal HbAlc glycaemic targets of $<7.0 \%$, which would not be feasible with a single oral agent $[22,23]$. Practitioners unanimously agree that the current treatment regimen of loose pills is scant of achieving good blood sugar control to ward off secondary health complications. The advantages of FDC as reviewed by Vijayakumar et al. [20] are found to be multi-tiered, ranging from better tolerability and bio-availability, to decreased medical expenditure and less discomfort associated with swallowing multiple tablets over single ones. However, in the real-world setting, the percentage of patients adopting FDC is actually quite low. In Mauritius, the public health sector remains one of the major sources for the supply of diabetes medication, but FDC is currently not offered as part of the 'free treatment' plan, so overall diabetes management is still observed to be 'moderately poor' amongst adults diagnosed with T2DM [24]. The present study aims at exploring patients' perspectives on FDC therapy in the management of T2DM and to understand the gap in treatment practice within the public health care setting which seems to be limiting the progressive decline of uncontrolled glycaemic control across the T2DM population in Mauritius.

\section{Materials and Methods}

\section{Study settings}

A total of 65 patients attending the Diabetes and Vascular Health Centre were earmarked to participate in this study. Medical records, i.e. case-sheets of patients who are on fixed-dose combination therapy and standard medication, were accessed. Inclusion criteria was: patients clinically diagnosed with T2DM, 18 years old and above, on at least two classes of oral hypoglycaemic agents or on fixed-dose combination tablets. Patients who either suffered from type 1 diabetes mellitus or gestational diabetes, as well as those on insulin therapy or less than two classes of oral hypoglycaemic agents as separate pills were automatically excluded. The participants were segmented into four groups according to their current and previous treatments: Group A - on FDC since start of treatment; Group B - switched from separate pills to FDC during treatment; Group C - on separate pills since start of treatment; and Group D - on FDC for a short time before reverting to separate pills (Figure 1). A non-probabilistic sampling strategy was used for Group A, B, and D, while participants from group C were chosen based on their adherence to clinical appointments and willingness to participate.

\section{Data Collection \& Analysis}

Using a mixed-method strategy, a pre-tested, self-designed questionnaire consisting of five sections inclusive of the patient's biodata, medical history and clinical parameters, compliance to diabetes management, attitudes towards medications, knowledge and attitudes to fixed-dose combination therapy was administered individually. A focus group was conducted to probe into potential existing issues with the current treatments and fixed dose combination tablets. Data was analysed using SPSS (v 23.0) using Pearson's chisquared test and Mann-Whitney U-test to measure group-based differences for non-parametric values. The level of significance was set at $\mathrm{P}<0.05$.

\section{Reliability}

Reliability within each dimension was tested factoring subjectivity and masked responses given that the data was collected by the healthcare professionals involved in their treatment. The following values were recorded: Compliance, $\alpha=0.496$; Attitude to medication, $\alpha=0.410$; and knowledge and attitude to FDC, $\alpha=0.577$. The mean inter-item correlation per dimension was calculated and found to be within the range of $0.2-0.4$ deemed to produce an optimal level of homogeneity [25].

\section{Ethics}

Ethical clearance for this study was granted by the Ministry of Health and Quality of Life (\#MHC/CT/NETH/OZM).

\section{Results}

\section{Population demographics and current health status}

The sample population consisted of a higher percentage of male patients (male vs female: $52.3 \%$ vs $47.7 \%$ ) from all the 4 groups. 
An exception was noted for Group B, i.e. patients who shifted from loose pills to FDC, as a higher number of female patients were more willing to transition to a new therapeutic method compared to males (female vs male: $59.3 \%$ vs $40.7 \%$ ). A low employment status (33\%) and high literacy rate (83.3\%) was observed in Group A as opposed to Group B whereby $55.5 \%$ were actively employed and contrastingly were from a basic educational background (63\% at a primary level) (Table 1). Findings also reported a shift towards FDC occurring towards the later stages of life, with $77.7 \%$ patients above the age of 50 years under such treatment. Clinical parameters showed some common traits across groups such as Body Mass Index (BMI) of approximately $40-67 \%$ patients categorized as overweight. Patients who were on FDC since the start of treatment or shifted to FDC mid treatment had a better blood pressure profile with $63-68 \%$ achieving a ratio of less than $140 / 90 \mathrm{mmHg}$, as opposed to those still on separate pills therapy (Table 2). These findings were further supported by the strong association (Cramer's $\mathrm{V}=0.322$ ) between treatment type and the blood pressure profile $(\mathrm{X} 2(6)=13.52, \mathrm{p}<0.05)$; and the clear difference between patients on or who shifted to FDC versus patients on separate pills (Group A vs Group C, 56.00 vs 505.00, U = 35.00, p $=0.02$; Group B vs Group C, 565.00 vs 920.00, U = 187.00, p = 0.001); results confirming a higher blood pressure profile among patients on conventional treatment, i.e. separate pills. Other clinical parameters such as serum cholesterol and creatinine were not affected by the treatment methods given the relatively similar levels across the groups.

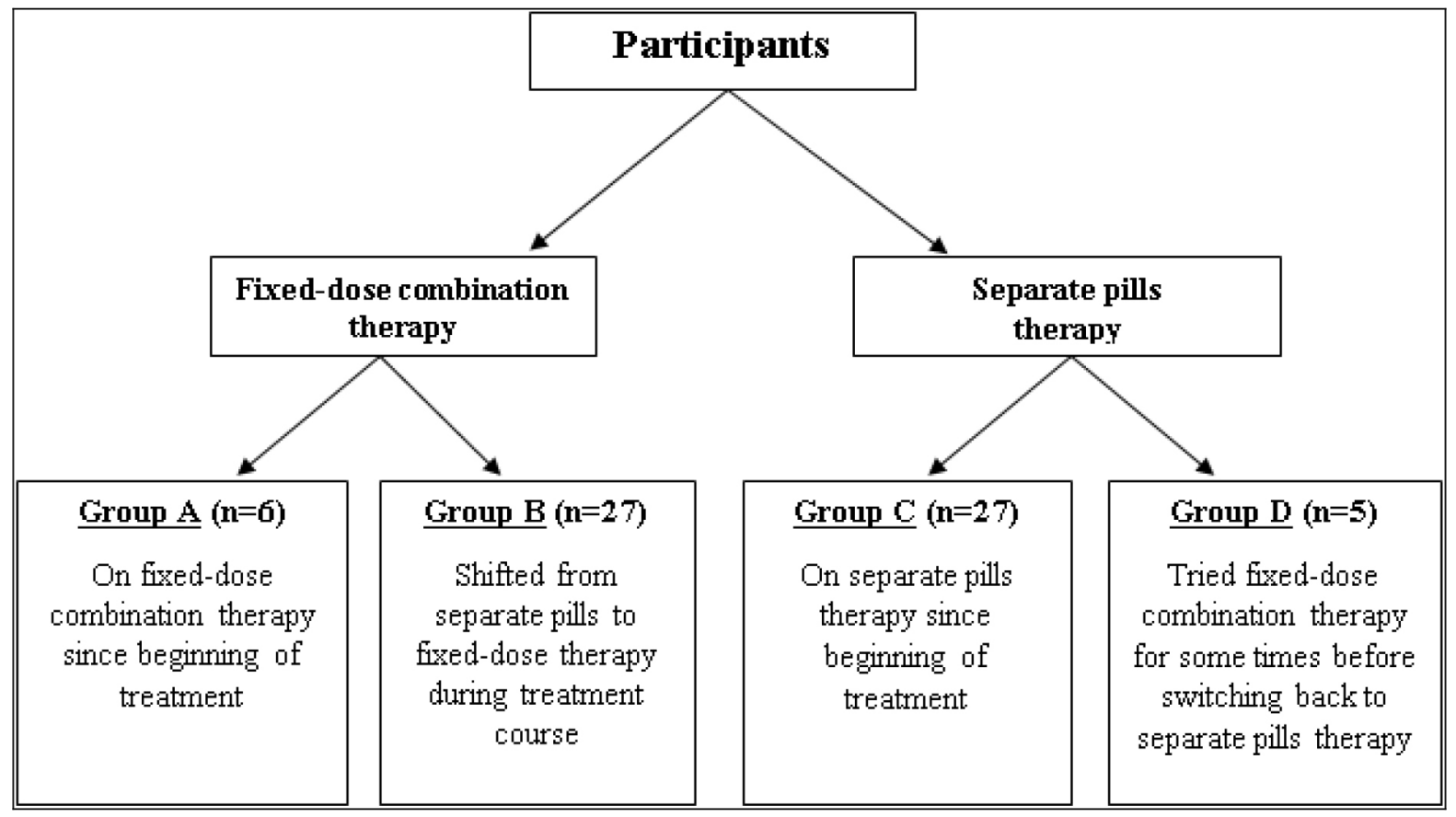

Figure 1. Grouping of participants based on previous and on-going diabetic treatment plan.

\section{Glycaemic index across and within treatment groups}

$44.6 \%$ of the patients had a long history of diabetes, i.e. more than 10 years. Analysis of their current glycemic parameters revealed a potentially higher proportion of patients from Group A and B with fasting blood sugar (FBS) levels of less than $7 \mathrm{mmol} / \mathrm{L}$, however, no concrete association was distinguished between the treatment group and their immediate glycemic index which could be accounted by $66-78 \%$ patients having an FBS level of less than $8.4 \mathrm{mmol} / \mathrm{L}$ across the different groups (Figure $2 \mathrm{~A}$ ). The glycemic index within group $\mathrm{B}$ showed a strong association (Cramer's $\mathrm{V}=0.451$ ) with respect to FBS levels and treatment stage, i.e. prior to and after switching to FDC $(\mathrm{X} 2(3)=10.991, \mathrm{P}<0.05)$. Non-parametric paired Wilcoxon Signed Ranks test showed improved FBS levels post-FDC treatment switch with 17 patients scoring better after resorting to FDC therapy $(\mathrm{Z}=$ -3.570, $\mathrm{P}<0.001$ ) (Figure 2A). Although similar associations were not drawn for HbA1c levels $(\mathrm{P}=0.093)$, related findings were observed when comparing the $\mathrm{HbA} 1 \mathrm{c}$ levels pre and post FDC treatment switch $(\mathrm{Z}=-3.441, \mathrm{P}=0.001)$ advocating the efficiency of FDC treatment on the net amelioration of glycemic parameters (Figure $2 \mathrm{~B}$ ).

\section{Pill burden, complexity of treatment and adherence to medication}

As detailed in Table 3, $67.7 \%$ of patients were taking more than 7 pills a day, while $24.6 \%$ were on both oral hypoglycemic agents and insulin therapy. The majority patients from group $\mathrm{C}$ had a higher daily pill intake for diabetes and associated diseases (85.2\%) as compared to group A (33.3\%) and B (51.9\%) supporting the association between treatment group and total number of prescribed medications (X2(6) $=18.229, \mathrm{p}<0.001)$ (Table 3). Patients from Group A reported to have never missed their diabetic medication compared to group B (85.5\%) and group C (77.8\%) who admitted to have missed their diabetes medications more than 3 times.. The data strongly supported 
the association between increasing treatment complexity across the groups and number of pills remaining $(\mathrm{X} 2(9)=19.048, \mathrm{P}<0.05)$; with higher number of pills remaining for group $\mathrm{C}$ versus $\mathrm{B}$ patients ( 918.50 vs 566.50 ; $\mathrm{U}=188.50, \mathrm{P}<0.01$ ). Prime cause was confusion due to increased number of pills to be taken (Figure 3). Other listed justifications such as forgetting to take pills, need help at home to take pills, taking pills over time become more difficult, feel taking too many medications, feeling anxious when having to take pills, deliberately omitting pills, portioning or taking extra medication did not seem to differ much in terms of behavioral attitudes across groups. However, in terms of monthly pill renewal, no marked discrepancies were found between the 4 groups $(\mathrm{X} 2(3)=3.08, \mathrm{P}>0.05)$, as all patients from were regular on their medication renewal. Moreover, since $92.3 \%$ of patients also suffered from other associated diseases (50 patients with co-existing hypertension and 39 patients suffering from dyslipidemia), the ability to distinguish and map the different classes of medication to the treating disease was assessed. Results showed a near significant association between those two dimensions $(\mathrm{X} 2(2)=$ $5.32, \mathrm{P}=0.07)$ with group $\mathrm{C}$ having a handicap in terms of medication mapping as compared to group $\mathrm{B}$ (820.50 vs 664.50 ; $\mathrm{U}=286.50, \mathrm{P}<$ $0.05)$. This supports the claim that FDC indeed decreases complexity of treatment in general.

Table 1. Demographic profile of study participants $(\mathrm{N}=65)$.

\begin{tabular}{|c|c|c|c|c|}
\hline Gender & Group A & Group B & Group C & Group D \\
\hline Male & $66.7 \%$ & $40.7 \%$ & $55.6 \%$ & $80 \%$ \\
\hline Female & $33.3 \%$ & $59.3 \%$ & $44.4 \%$ & $20 \%$ \\
\hline \multicolumn{5}{|l|}{ Age } \\
\hline$<40$ years & - & $7.4 \%$ & - & - \\
\hline 40-49 years & - & $14.8 \%$ & $14.8 \%$ & - \\
\hline 50-59 years & $50 \%$ & $29.6 \%$ & $25.9 \%$ & $60 \%$ \\
\hline$\geq 60$ years & $50 \%$ & $48.1 \%$ & $59.3 \%$ & $40 \%$ \\
\hline \multicolumn{5}{|l|}{ Occupation } \\
\hline Employed & $33.3 \%$ & $18.5 \%$ & $29.6 \%$ & $40 \%$ \\
\hline Self-employed & - & $14.8 \%$ & $25.9 \%$ & $40 \%$ \\
\hline Housewife & $16.7 \%$ & $22.2 \%$ & $18.5 \%$ & - \\
\hline Retired & $33.3 \%$ & $29.6 \%$ & $25.9 \%$ & - \\
\hline Not employed & $16.7 \%$ & $14.8 \%$ & - & $20 \%$ \\
\hline \multicolumn{5}{|l|}{ Education level } \\
\hline None & $16.7 \%$ & $7.4 \%$ & $18.5 \%$ & - \\
\hline Primary & - & $37 \%$ & $63 \%$ & $40 \%$ \\
\hline Secondary & $33.3 \%$ & $40.7 \%$ & $18.5 \%$ & $20 \%$ \\
\hline Tertiary & $50 \%$ & $14.8 \%$ & - & $40 \%$ \\
\hline
\end{tabular}

Group A - on FDC since start of treatment; Group B - switched from separate pills to FDC during treatment; Group C - on separate pills since start of treatment; and Group D - on FDC for a short time before reverting to separate pills
Table 2. Health Status of study participants $(\mathrm{N}=65)$

\begin{tabular}{|c|c|c|c|c|}
\hline Clinical Parameters & Group A & Group B & Group C & Group D \\
\hline \multicolumn{5}{|l|}{$B M I\left(K g / m^{2}\right)$} \\
\hline Normal & $16.7 \%$ & $44.4 \%$ & $18.5 \%$ & $20 \%$ \\
\hline Overweight & $66.7 \%$ & $40.7 \%$ & $40.7 \%$ & $60 \%$ \\
\hline Obese & $16.7 \%$ & $14.8 \%$ & $40.7 \%$ & $20 \%$ \\
\hline \multicolumn{5}{|c|}{ Blood Pressure ( $\mathrm{mmHg}$ ) } \\
\hline$<140 / 90$ & $66.7 \%$ & $63 \%$ & $22.2 \%$ & $40 \%$ \\
\hline $140-159 / 90-99$ & $33.3 \%$ & $29.6 \%$ & $40.7 \%$ & $40 \%$ \\
\hline $160-179 / 100-109$ & - & $7.4 \%$ & $37 \%$ & $20 \%$ \\
\hline$\geq 180 / 110$ & - & - & - & - \\
\hline \multicolumn{5}{|c|}{ Serum Total Cholesterol $(\mathrm{mmol} / \mathrm{L})$} \\
\hline$<4.5$ & $66.7 \%$ & $66.7 \%$ & $63 \%$ & $60 \%$ \\
\hline$\geq 4.5$ & $33.3 \%$ & $33.3 \%$ & $37 \%$ & $40 \%$ \\
\hline \multicolumn{5}{|c|}{ Serum Creatinine (umol/L) } \\
\hline$<124$ & $100 \%$ & $96.3 \%$ & $96.3 \%$ & $100 \%$ \\
\hline$\geq 124$ & - & $3.7 \%$ & $3.7 \%$ & - \\
\hline
\end{tabular}

Group A - on FDC since start of treatment; Group B - switched from separate pills to FDC during treatment; Group C - on separate pills since start of treatment; and Group D - on FDC for a short time before reverting to separate pills

Table 3. Diabetes and associated diseases' medication profile.

\begin{tabular}{|c|c|c|c|c|}
\hline $\begin{array}{l}\text { Classes of oral diabetes } \\
\text { medications }\end{array}$ & Group A & Group B & Group C & Group D \\
\hline 2 classes & $50 \%$ & $59.3 \%$ & $100 \%$ & $80 \%$ \\
\hline 3 classes & $50 \%$ & $40.7 \%$ & - & - \\
\hline 4 classes & - & - & - & $20 \%$ \\
\hline \multicolumn{5}{|c|}{ Number of diabetes pills/day } \\
\hline $1-3$ pills & $66.7 \%$ & $55.6 \%$ & $7.4 \%$ & $20 \%$ \\
\hline 4-6 pills & $33.3 \%$ & 33.3 & $29.6 \%$ & $80 \%$ \\
\hline 7-9 pills & - & 11.1 & $63 \%$ & - \\
\hline 10-12 pills & - & - & - & - \\
\hline \multicolumn{5}{|l|}{ Total number of pills/day } \\
\hline $1-3$ pills & $33.3 \%$ & $7.4 \%$ & - & - \\
\hline 4-6 pills & $33.3 \%$ & $40.7 \%$ & $14.8 \%$ & - \\
\hline$\geq 7$ pills & $33.3 \%$ & $51.9 \%$ & $85.2 \%$ & $100 \%$ \\
\hline
\end{tabular}

Group A - on FDC since start of treatment; Group B - switched from separate pills to FDC during treatment; Group C - on separate pills since start of treatment; and Group D - on FDC for a short time before reverting to separate pills 
A

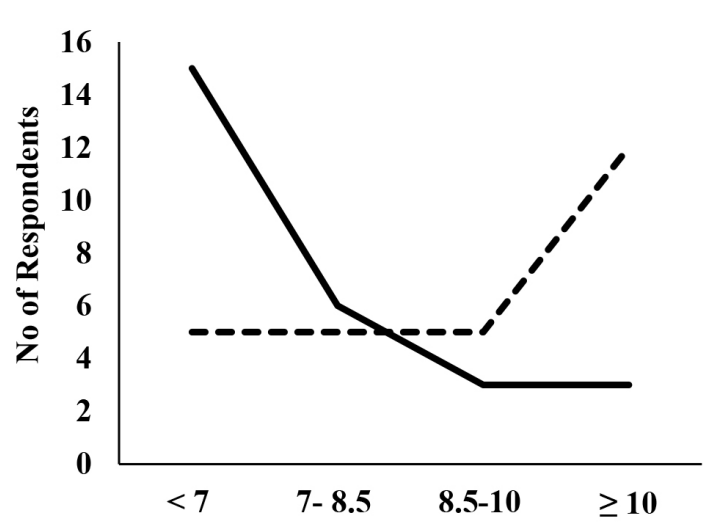

FBS Levels (mmol/L)
B

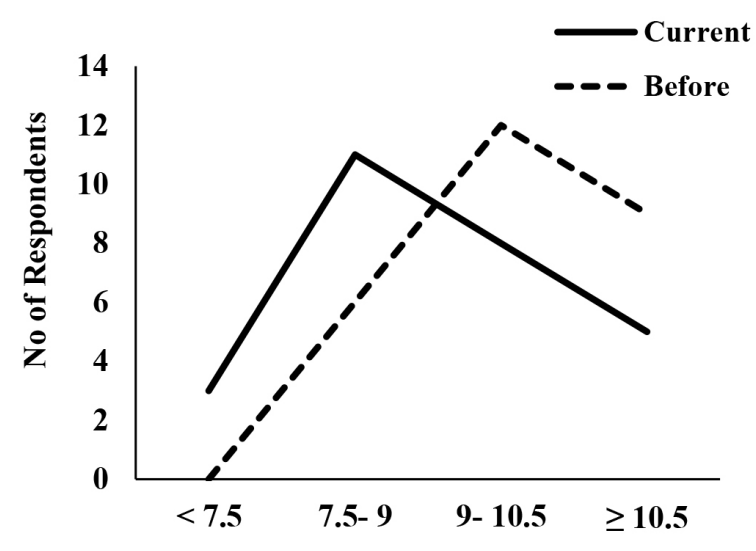

HbA1c Levels (\%)

Figure 2. (A) Fasting blood sugar (FBS) levels (B) HbAlc levels recorded in patients who shifted to fixed dose combination (FDC) from separate pills. (Solid line - current levels recorded, Dotted lines - levels measured prior to FDC switch)

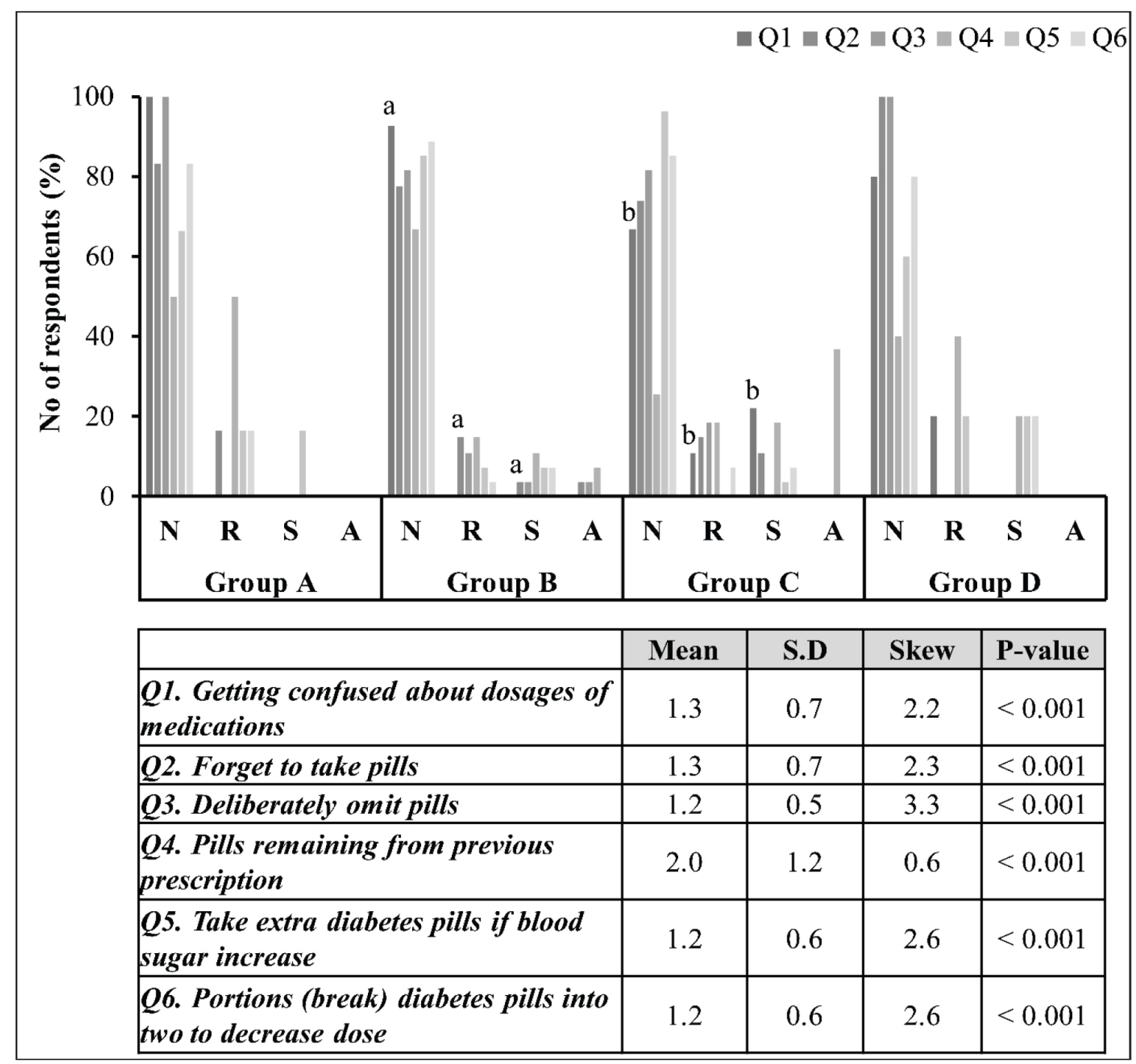

Figure 3. Perception of pill burden across treatment groups

$\mathbf{N}$, never; $\mathbf{R}$, rarely; $\mathbf{S}$, sometimes; and $\mathbf{A}$, always. $\mathbf{P}<0.05$. Group $\mathbf{A}-$ on FDC since start of treatment; $\mathbf{G r o u p ~} \mathbf{B}-$ switched from separate pills to FDC during treatment; Group $\mathbf{C}$ - on separate pills since start of treatment; and Group D - on FDC for a short time before reverting to separate pills 


\section{Adherence to general diabetes recommendations}

$44 \%$ of patients from group B acquired their diabetes medication both from private and public medical facilities. However, the public sector remains one of the major sources for diabetes medication supply in Mauritius. $90.8 \%$ of patients stated that they had received counselling and explanation on how and when to take their medications. $40 \%$ of patients from groups $\mathrm{C}$ and $\mathrm{D}$ also admitted to having missed their appointment with the healthcare practitioner. Of concern, $66.7 \%$ from group $\mathrm{C}$ did not have access to a glucometer to monitor their glucose levels at regular intervals, thus heavily depended on public health services (Table 4). With respect to lifestyle choices $40-70 \%$ of patients indulged in unhealthy eating behavior, which reflects a lack of stringency with respect to their dieting habits.

Table 4. Lifestyle and health check status among diabetes patients under different treatment.

\begin{tabular}{|l|c|c|c|c|}
\hline & Group A & Group B & $\begin{array}{c}\text { Group } \\
\text { C }\end{array}$ & $\begin{array}{c}\text { Group } \\
\text { D }\end{array}$ \\
\hline Practising Exercise & $66.7 \%$ & $81.5 \%$ & $70.4 \%$ & $60 \%$ \\
\hline $\begin{array}{l}\text { Intake of unhealthy } \\
\text { foodstuffs }\end{array}$ & $44.4 \%$ & $44.4 \%$ & $45.7 \%$ & $66.70 \%$ \\
\hline $\begin{array}{l}\text { Patients compliant } \\
\text { to medication intake } \\
\text { instructions }\end{array}$ & $100 \%$ & $88.9 \%$ & $74.1 \%$ & $80 \%$ \\
\hline $\begin{array}{l}\text { Patients missing/delaying } \\
\text { their appointment with } \mathrm{HCP}\end{array}$ & $0 \%$ & $11.1 \%$ & $18.5 \%$ & $40 \%$ \\
\hline $\begin{array}{l}\text { Patients renewing their } \\
\text { medications on time }\end{array}$ & $100 \%$ & $96.3 \%$ & $96.3 \%$ & $80 \%$ \\
\hline $\begin{array}{l}\text { Patients attending for } \\
\text { diabetic retinopathy } \\
\text { screening }\end{array}$ & $83.3 \%$ & $100 \%$ & $77.8 \%$ & $100 \%$ \\
\hline $\begin{array}{l}\text { Patients attending for } \\
\text { diabetic foot screening }\end{array}$ & $66.7 \%$ & $85.2 \%$ & $70.4 \%$ & $80 \%$ \\
\hline \begin{tabular}{l} 
Patients using a glucometer \\
\hline
\end{tabular} & $100 \%$ & $85.2 \%$ & $33.3 \%$ & $60 \%$ \\
\hline
\end{tabular}

Group A - on FDC since start of treatment; Group B - switched from separate pills to FDC during treatment; Group C - on separate pills since start of treatment; and Group $\mathbf{D}$ - on FDC for a short time before reverting to separate pills

\section{Attitude and barriers towards adoption of FDC}

Only $30.8 \%$ of patients were aware that 2 or more active medication ingredients may be present in a single pill, whereas only $54.6 \%$ were aware that FDC therapy consisted of two active diabetes medications. $84.6 \%$ of patients agreed that FDC was important to decrease pill burden, with patients from group C and D expressing their willingness to move to FDC if made available in the public health care sector (96.3 and 80\% respectively). Cost, on the other hand, was believed to be the most common drawback for using FDC (Figure 4).

\section{Discussion}

\section{Impact of treatment type on systemic clinical parameters}

While no association was depicted among clinical parameters such as BMI, serum creatinine and serum total cholesterol, across the treatment groups, blood pressure (BP) control significantly differed for patients who were on FDC versus those on separate pills, aligning with studies which have demonstrated a better blood pressure control in T2DM patients under anti-hypertensive and antidiabetic FDC treatment [26]. 77.7\% of patients on loose pills in our study were affected by high BP, which would warrant the use of FDC therapy targeting both their diabetic and hypertensive pathologies to ameliorate their health status as recommended by the American Diabetes Association [27]. Pathology-specific FDC treatment appears to play a vital role in managing T2DM to reach the ultimate target of achieving a blood pressure of $<140 / 90 \mathrm{mmHg}$ among those patients. Among other health status determinants, a closer examination of BMI across groups revealed an obesity index of $40 \%$ vs. $14.8 \%$ among participants on separate pills and FDC respectively. Majority of patients $(92.3 \%)$ had associated conditions, mainly hypertension and dyslipidemia, reflecting the long years, i.e. more than 10 years with a diabetic condition and supporting the notion of augmented risk of developing comorbid conditions with increased disease duration [28]. Interestingly, BMI adds to the equation whereby increase in BMI heightens the prevalence rate of hypertension, diabetes, and dyslipidemia $[29,30]$, validating the measures of those clinical parameters in the assessment of $\mathrm{T} 2 \mathrm{DM}$ and treatment strategies. Restoring normal BMI through exercise and diet has been proved to positively contribute to the control of glycaemic index and lipid profile $[31,32]$. The present study did not overlook the eating and exercising habits of the participants. Overall, a week prior to the study, $44.6 \%$ participants used sugar, $60 \%$ took some forms of sweet and $35.4 \%$ had soft drinks, which shows the poor compliance in to dietary recommendations in accordance with other studies [33] and which may attributed to the perception of diet as a burden [34]. Therefore, modifying behavioural attitude towards clinically recommended lifestyle habits and treatment options may prove to enhance diabetic control.

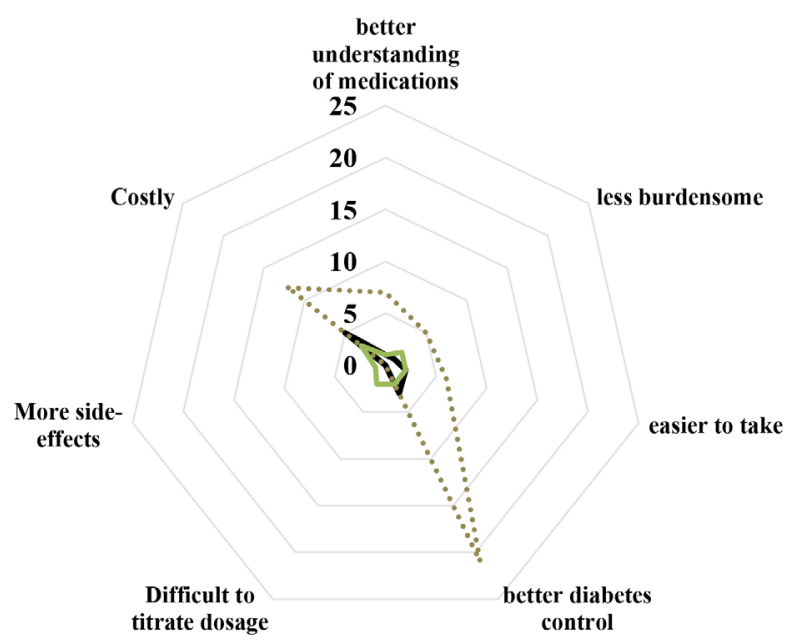

Figure 4. Attitudes and barriers towards adoption of fixed dose therapy amongst participants $(\mathrm{N}=65)$

\section{FDC as a measure to improve glycaemic index in T2DM patients}

No significant differences were recorded with respect to glycaemic index across the groups However; probing further into group B (patients who shifted from separate pills to FDC) a major 
improvement was depicted in their FBS and HbAlc levels, which is in line with findings of Thayer et al. [35] who a reported decrease in HbA1c levels following a swap from mono-therapeutic agents to a rosiglitazone/glimepiride FDC treatment. Similarly, Raskin et al. [36] demonstrated the ability of coupling repaglinide/metformin as an FDC regimen to induce a more rapid decrease in HbAlc levels, as opposed to monotherapy. The present findings are in support of such clinical studies which claim that lower doses of 2 agents in fixed combinations may offer greater efficacy in combination, at the same time reducing the risk of adverse events that may occur with higher doses of monotherapy [37].

\section{Conventional therapies and failure to adhere to medication and general recommendations}

Medication adherence is closely related to the drug regimen of the patients. The progressive nature of T2DM and its potent role in the generation of non-communicable diseases [38], increases by default the treatment spectrum to encompass the associated complications. A staggering $70 \%$ of patients in the present study were on more than 7 pills for diabetes and comorbid disease regulation. Pill burden is a major thorn in keeping T2DM treatment on track. A 5-year study on the change in medication profile after onset of diabetes, revealed an increase in pills targeting the cardinal comorbidities such as hypertension and dyslipidemia. Comparative analysis of the 4 treatment groups identified the following drawbacks whilst on loose pill therapy: difficulty in preparing doses, extended time taken to medicate, accidental mixing tablets/doses, as well as the overall cost of medication $[39,40,41,8]$, compared to those of FDC, the latter who were more rigid on their treatment schedule and pills intake. Moreover, compared to groups $\mathrm{A}$ and $\mathrm{D}$, a significantly proportion of patients from group $\mathrm{C}$ had pills remaining when at the time of their next appointment, implying the notion of pill burden and noncompliance majorly associated to conventional therapies. Studies by up-titration, a core process in monotherapy, is streamlined or reduced in FDC, positively impacting the effects of pill burden as well as decreasing the adverse effects prevailing from high up-titrated doses of anti-diabetic agents [42].

Lifestyle factors play a critical role in the pre-disposition and management of T2DM. Considering the recommendations of the American Diabetes Association [27], a diet consisting of food with low glycaemic load and reduced sugar levels achieves better FBS control. Additionally, diet plans inclusive of high-unsaturated/low-saturated fat diet [43], low-glycaemic index diet [44], and low-carbohydrate ketogenic diets [45] have proved to be effective in normalizing the glycaemic index of T2DM patients. Physical activity routines including high-intensity progressive resistance training, and its modified version with coupled high-protein diet have been found to be effective in weight loss and improvements in glycaemic parameters [46, 47]. Our study showed that majority participants across all treatment groups were non-compliant with the recommendations as indicated by a meagre $26 \%$ engaged in physical activity for more than 3 times a week; and $50 \%$ with poor dieting habits. This could potentially be attributed to the lack of self-management know-how and unstimulated interests in self-care strategies, warranting better educational frameworks to be implemented in Mauritius to help improve lifestyle decisions amongst diabetics [48].

\section{Knowledge, benefits and barriers to FDC: Patients' perspective}

Health literacy has a great impact on adherence and severity of illness perception such that low and moderate literacy among patients augments the perception of diabetes or co-morbid illnesses as 'threatening' which impairs medical adherence. The present data does not significantly point to perceptions of similar nature, but, $30-40 \%$ of patients from group B and C were in agreement of the stated perception. Therefore, the suggested role of health literacy as a protective factor in terms of medical adherence may be dependent on socio-economic status of the patients. A study by Powell et al. [49] explored and demonstrated the detrimental impacts of poor health literacy on declining glycaemic control. Our data showed similar results in terms of knowledge of FDC amongst group $\mathrm{C}$ patients, where only $7 \%$ aware of the existence of FDC. Modality of drug functions were not well spread among patients given that only $55 \%$ of patients on FDC were aware of its mechanism of action with a combination of two active ingredients. Poor knowledge of FDC could be attributed to a lack of knowledge about diabetes, public policies and availability of medication in public institutions; and clinical inertia [50, 51, 52]. In Mauritius, FDC is not part of the welfare programme, hence it cannot be prescribed by public health care professionals to T2DM patients. Such public policy matters are also of concern in countries such as Canada [53]. Clinical inertia, on the other hand, has developed into a prominent issue in the regulation of glycaemic index among T2DM patients and justifications for such stagnancy in treatment have been tossed between the patient and clinician. A fundamental approach towards reducing clinical inertia revolves around the education and continuous training of clinicians to be up-to-date with modern pharmaceutical agents and treatment strategies available for the betterment of the T2DM patients $[54,55]$.

A pertinent finding from this study was the impact FDC on the quality of life (QOL) of patients, specifically with respect to mental health. Patients from group A were not anxious during medication time as opposed to patients from group $\mathrm{C}$, reports which corroborate data from Heckbert et al. [56] highlighting the association between patients with uncontrolled $\mathrm{HbA} 1 \mathrm{c}$ levels and depression. Identification of psychosocial determinants which may exacerbate poor glycaemic control and adherence is important during the early stages of diabetes diagnosis as progression of disease and its associated treatment intensification may lead to a perception of failure in the day-today management of diabetes further demotivating the patient [57]. Treating mental health irregularities may also prove to be beneficial in strengthening the sustenance of healthy lifestyle habits in T2DM [58], hence the decrease in anxiety which is mediated by FDC appears to be a good indicator of the functionality of this therapeutic method on patients' QoL.

\section{FDC - cost implication of lifelong treatment}

In the present study, cost was cited as being the prime justification for reverting back to separate pills therapy in group $\mathrm{D}$ patients. This was 
further supported by the fact that $25 \%$ of patients were complementing medications received in the public sector with medications bought from private pharmacies leading to drug wastage and mediated by the inability of the welfare programme and insurance policies to cover the FDC pills. T2DM patients have high medical costs, averaging $\$ 14,000$ as a result of the direct and indirect costs associated to the treatment of diabetes and its co-morbid conditions [59]. Similarly, Indian patients on loose pills therapy spend a monthly average of 216 rupees which roughly amounts to the cost of one FDC pill [60]- a situation which is replicated in Mauritius given that this type of treatment is not covered by the healthcare welfare; further endorsing an in-depth situational analysis and revamping of the medical coverage and treatment availability in the public sector. The call for a review of the anti-diabetic medication dispensing programme is further warranted given that FDC-associated costs are reported to be the inverse to what is claimed by the National Institute for Health and Clinical Excellence, with a yearly expenditure of approximately $\$ 1600$ on FDC vs. $\$ 1900$ on separate pills $[61,62]$. Interestingly, many FCD respondents who mentioned that the pill strength was too high, which is relevant given the inflexibility of FDC and tailoring of dosage to individual characteristics inclusive of demographics and pharmacogenetics [63].

\section{Conclusion}

Our findings contribute to the scarcity of information pertaining to the patients' outlook on T2DM treatment with emphasis on fixed dose combination therapy in Mauritius. Although being a welfare state which provides health care services free of charge, our findings have highlighted the consensus that medications from the public hospitals in the form of loose pills are burdensome, resulting in ineffective diabetes and co-morbidity management. Moreover, the relevance of patient empowerment in doctor-patient consultations should not be overlooked when challenged with finding solutions to reduce global incidence of hyperglycemia and adverse effects in dual therapy with individual components.

\section{Contribution}

MYO: study design and data collection; MP and JSB: study design, statistical analysis, manuscript editing and writing. All authors read and approved the final manuscript.

\section{Acknowledgement}

Authors would like to acknowledge the Ministry of Health and Quality of Life for granting access to relevant medical records, and the staff at Diabetes and Vascular Health Centre, Souillac for their support.

\section{References}

1. Trikkalinou A, Papazafiropoulou AK, Melidonis A (2017) Type 2 diabetes and quality of life. World J Diabetes 8: 120-129. [crossref]

2. International Diabetes Federation. IDF Diabetes Atlas 8th edition. Brussels, Belgium: International Diabetes Federation, 2017. Available: http: //www. diabetesatlas.org

3. International Diabetes Federation. Recommendations For Managing Type 2 Diabetes In Primary Care, 2017. Available: www.idf.org/managing-type2-diabetes

4. Druss BG, Marcus SC, Olfson M, Tanielian T, Elinson L, Pincus HA (2001) Comparing the national economic burden of five chronic conditions. Health Aff (Millwood) 20: 233-241
5. Blüher M, Kurz I, Dannenmaier S, Dworak M (2015) Pill Burden in Patients With Type 2 Diabetes in Germany: Subanalysis From the Prospective, Noninterventional PROVIL Study. Clin Diabetes 33: 55-61. [crossref]

6. Feldman BS, Cohen-Stavi CJ, Leibowitz M, Hoshen MB, Singer SR, et al. (2014) Defining the role of medication adherence in poor glycemic control among a general adult population with diabetes. PLoS One 9: 108145. [crossref]

7. Chawla A, Chawla R, Jaggi S (2016) Microvasular and macrovascular complications in diabetes mellitus: Distinct or continuum? Indian J Endocrinol Metab 20: 546 551. [crossref]

8. García-Pérez LE, Alvarez M, Dilla T, Gil-Guillén V, Orozco-Beltrán D (2013) Adherence to therapies in patients with type 2 diabetes. Diabetes Ther 4: 175-194. [crossref]

9. Bailey CJ, Kodack M (2011) Patient adherence to medication requirements for therapy of type 2 diabetes. Int J Clin Pract 65: 314-322

10. Rozenfeld Y, Hunt JS, Plauschinat C, et al (2008) Oral antidiabetic medication adherence and glycemic control in managed care. Am J Manag Care 14: 71-75

11. Pantuzza LL, Ceccato MGB, Silveira MR, Junqueira LMR, Rei AMM (2017) Association between medication regimen complexity and pharmacotherapy adherence: a systematic review. Eur J Clin Pharmacol 73: 1475-1489

12. Claxton AJ, Cramer J, Pierce C (2001) A systematic review of the associations between dose regimens and medication compliance. Clin Ther 23: 1296-1310

13. Gonzalez JS, Tanenbaum ML, Commissariat PV (2016) Psychosocial Factors in Medication Adherence and Diabetes Self-Management: Implications for Research and Practice. Am Psychol 71: 539-551

14. Brown MT, Bussell JK (2011) Medication adherence: WHO cares? Mayo Clin Proc 86: 304-314. [crossref]

15. Abughosh SM, Wang X, Serna O, et al (2016) A pharmacist telephone intervention to identify adherence barriers and improve adherence among nonadherent patients with comorbid hypertension and diabetes in a medicare advantage plan. J Manag Care Spec Pharm 22: 63-73

16. Triplitt C (2010) Improving treatment success rates for type 2 diabetes: recommendations for a changing environment. Am J Manag Care 16: S195-S200

17. Grant R, Adams AS, Trinacty CM, Zhang F, Kleinman K, Soumerai SB, Meigs JB, Ross-Degnan D (2007) Relationship between patient medication adherence and subsequent clinical inertia in type 2 diabetes glycemic management. Diabetes Care 30: $807-812$

18. Reach G, Pechtner V, Gentilella R, Corcos A, Ceriello, A (2017) Clinical inertia and its impact on treatment intensification in people with type 2 diabetes mellitus. Diabetes \& Metabolism 43: 501-511

19. Pantalone KM, Misra-Hebert AD, Hobbs TM, Ji X, et al (2018) Clinical Inertia in Type 2 Diabetes Management: Evidence From a Large, Real-World Data Set. Diabetes Care 41: 113-113e114. [crossref]

20. Vijayakumar TM, Jayram J1, Meghana Cheekireddy V1, Himaja D1, Dharma Teja Y1, et al. (2017) Safety, Efficacy, and Bioavailability of Fixed-Dose Combinations in Type 2 Diabetes Mellitus: A Systematic Updated Review. Curr Ther Res Clin $\operatorname{Exp}$ 84: 4-9. [crossref]

21. Cheong C, Barner JC, Lawson KA, Johnsrud MT (2008) Patient adherence and reimbursement amount for antidiabetic fixed-dose combination products compared with dual therapy among Texas Medicaid recipients. Clin Ther 30: 1893-1907

22. Defronzo RA, Eldor R, Abdul-Ghani M (2013) Pathophysiologic Approach to Therapy in Patients With Newly Diagnosed Type 2 Diabetes. Diabetes Care 36: S127-S138

23. Han S, Iglay K, Davies MJ, Zhang Q, Radican L (2012) Glycemic effectiveness and medication adherence with fixed-dose combination or coadministered dual therapy of antihyperglycemic regimens: a meta-analysis. Curr Med Res Opin 28: 969-977

24. Mauritius Non-Communicable Diseases (NCD) survey report. The Trends in Diabetes and Cardiovascular Disease Risk in Mauritius 2015. Available: http: // health.govmu.org/English/Statistics/Pages/NCD-Survey-Reports.aspx

25. Briggs SR, Cheek JM (1986) The role of factor analysis in the development and evaluation of personality scales. J Pers 54: 106-148

26. Weber MA, Bakris GL, Jamerson K, Weir M, Kjeldsen SE, et al. (2010) Cardiovascular events during differing hypertension therapies in patients with diabetes. J Am Coll Cardiol 56: 77-85. [crossref]

27. American Diabetes Association (2017) Standards of medical care in diabetes. Diabetes care 40: S11-24

28. Lopez Stewart G, Tambascia M, Rosas Guzmán J, Etchegoyen F, Ortega Carrión J, et al. (2007) Control of type 2 diabetes mellitus among general practitioners in private practice in nine countries of Latin America. Rev Panam Salud Publica 22: 12-20. [crossref]

29. Nguyen NT, Magno CP, Lane KT, Hinojosa MW, Lane JS (2008) Association of Hypertension, Diabetes, Dyslipidemia, and Metabolic Syndrome with Obesity: Findings from the National Health and Nutrition Examination Survey, 1999 to 2004. J Am Coll Surg 207: 928-934 
30. Cercato C, Mancini MC, Arguello AM, Passos VQ, Villares SM, Halpern A (2004) Systemic hypertension, diabetes mellitus, and dyslipidemia in relation to body mass index: evaluation of a Brazilian population. Rev Hosp Clin Fac Med Sao Paulo 59: 113-118

31. Boulé NG, Haddad E, Kenny GP, Wells GA, Sigal RJ (2001) Effects of Exercise on Glycemic Control and Body Mass in Type 2 Diabetes MellitusA Meta-analysis of Controlled Clinical Trials. JAMA 286: 1218-1227

32. Halle M, Berg A, Garwers U, Baumstark MW, Knisel W, et al. (1999) Influence of 4 weeks' intervention by exercise and diet on low-density lipoprotein subfractions in obese men with type 2 diabetes. Metabolism. 48: 641-664

33. Nelson KM, Reiber G, Boyko EJ; NHANES III (2002) Diet and exercise among adults with type 2 diabetes: findings from the third national health and nutrition examination survey (NHANES III). Diabetes Care 25: 1722-1728. [crossref]

34. Vijan S, Stuart NS, Fitzgerald JT, Ronis DL, Hayward RA, et al. (2005) Barriers to following dietary recommendations in Type 2 diabetes. Diabet Med 22: 32-38. [crossref]

35. Thayer S, Arondekar B, Harley C, Darkow TE (2010) Adherence to a FixedDose Combination of Rosiglitazone/Glimepiride in Subjects Switching from Monotherapy or Dual Therapy with a Thiazolidinedione and/or a Sulfonylurea. Ann Pharmacothr 44: 791-799

36. Raskin P, Lewin A, Reinhardt R, Lyness W (2009) Repaglinide/Metformin Fixed-Dose Combination Study Group. Twice-daily dosing of a repaglinide/ metformin fixed-dose combination tablet provides glycaemic control comparable to rosiglitazone/metformin tablet. Diabetes Obes Metab 11: 865-873

37. Abdulsalim S, Peringadi Vayalil M, Miraj SS (2016) New fixed dose chemical combinations: the way forward for better diabetes type II management? Expert Opin Pharmacother 17: 2207-2214. [crossref]

38. Chaudhury A, Duvoor C, Reddy Dendi VS, Kraleti S, Chada A, et al. (2017) Clinical Review of Antidiabetic Drugs: Implications for Type 2 Diabetes Mellitus Management. Front Endocrinol (Lausanne) 8: 6. [crossref]

39. Saundankar V, Peng X, Fu H, Ascher-Svanum H, Rodriguez A, et al. (2016) Predictors of Change in Adherence Status from 1 Year to the Next Among Patients with Type 2 Diabetes Mellitus on Oral Antidiabetes Drugs. JMPC 22: 467-482

40. Black JA, Simmons RK, Boothby CE, Davies MJ, Webb D, et al. (2015) Medication burden in the first 5 years following diagnosis of type 2 diabetes: findings from the ADDITION-UK trial cohort. BMJ Open Diabetes Res Care 3: 000075. [crossref]

41. Farrell B, French Merkley V, Ingar N (2013) Reducing pill burden and helping with medication awareness to improve adherence. Can Pharm J (Ott) 146: 262-269. [crossref]

42. Lavernia F, Adkins SE. Shubrook JH (2015) Use of oral combination therapy for type 2 diabetes in primary care: Meeting individualized patient goals. Postgraduate Medicine 127: 808-817

43. Tay J, Luscombe-Marsh ND, Thompson CH, Noakes M, Buckley JD, et al. (2014) A very low-carbohydrate, low-saturated fat diet for type 2 diabetes management: a randomized trial. Diabetes Care 37: 2909-2918. [crossref]

44. Jenkins DJA, Kendall CWC, Mckeown-Eyssen G, Josse RG, Silverberg J, Booth GL, et al. (2008) Effect of a Low-Glycemic Index or a High-Cereal Fiber Diet on Type 2 Diabetes: A Randomized Trial. JAMA 300: 2742-2753

45. Yancy WS Jr1, Foy M, Chalecki AM, Vernon MC, Westman EC (2005) A lowcarbohydrate, ketogenic diet to treat type 2 diabetes. Nutr Metab (Lond) 2: 34 [crossref]

46. Dunstan DW, Daly RM, Owen N, Jolley D, De Courten M, et al. (2002) Highintensity resistance training improves glycemic control in older patients with type 2 diabetes. Diabetes Care 25: 1729-1736. [crossref]

47. Wycherley TP, Noakes M, Clifton PM, Cleanthous X, Keogh JB, et al. (2010) A high-protein diet with resistance exercise training improves weight loss and body composition in overweight and obese patients with type 2 diabetes. Diabetes Care 33: 969-976. [crossref]

48. Davies MJ, Heller S, Skinner TC, Campbell MJ, Carey ME, et al. (2008) Effectiveness of the diabetes education and self-management for ongoing and newly diagnosed (DESMOND) programme for people with newly diagnosed type 2 diabetes: cluster randomised controlled trial. BMJ 336: 491-495. [crossref]

49. Powell CK, Hill EG Clancy DE (2007) The Relationship between Health Literacy and Diabetes Knowledge and Readiness to Take Health Actions. Diabetes Educ 33: 144-151

50. Abbasi YF, See OG, Ping NY, Balasubramanian GP, Hoon YC, et al. (2018) Diabetes knowledge, attitude, and practice among type 2 diabetes mellitus patients in Kuala Muda District, Malaysia - A cross-sectional study. Diabetes Metab Syndr 12: 1057-1063. [crossref]

51. Kueh YC, Morris T Ismail AAS (2017) The effect of diabetes knowledge and attitudes on self-management and quality of life among people with type 2 diabetes. $J$ Health Psychol 22: 138-144

52. Pashaki MS, Eghbali T, Niksima SH, Albatineh AN Gheshlagh RG (2019) Health literacy among Iranian patients with type 2 diabetes: A systematic review and metaanalysis. Diabetes Metab Syndr 13: 1341-1345
53. Canadian Diabetes Association (2019)Diabetes Canada's Position on Government Efforts to Control Drug Costs. Available: https: //www.diabetes.ca/about-cda/ public-policy-position-statements/government-efforts-to-control-drug-costs

54. Shera AS, Jawad F Basit A (2002) Diabetes related knowledge, attitude and practices of family physicians in Pakistan. J Pak Med Assoc 52: 465-470

55. Goswami N, Gandhi A, Patel P, Dikshit R (2013) An evaluation of knowledge, attitude and practices about prescribing fixed dose combinations among resident doctors. Perspect Clin Res 4: 130-125

56. Heckbert SR, Rutter CM, Oliver M, Williams LH, Ciechanowski P, et al. (2010) Depression in relation to long-term control of glycemia, blood pressure, and lipids in patients with diabetes. $J$ Gen Intern Med 25: 524-529. [crossref]

57. Ross SA (2013) Breaking down patient and physician barriers to optimize glycemic control in type 2 diabetes. Am J Med 126: S38-48. [crossref]

58. Petrak, F, Baumeister H, Skinner TC, Brown A Holt RIG (2015) Depression and diabetes: treatment and health-care delivery. Lancet Diabetes Endocrinol 3: 472485

59. Zhuo X, Zhang P, Barker L, Albright A, Thompson TJ, et al. (2014) The lifetime cost of diabetes and its implications for diabetes prevention. Diabetes Care 37: 2557-2564. [crossref]

60. Kannan S, Mahadevan S, Ramakrishnan A (2015) Fixed dose combinations for type 2 diabetes. Lancet Diabetes Endocrinol 3: 408. [crossref]

61. Clarke PM1, Avery AB2 (2014) Evaluating the costs and benefits of using combination therapies. Med J Aust 200: 518-520. [crossref]

62. Hutchins V, Zhang B, Fleurence R L, Krishnarajah G, Graham J (2011) A systematic review of adherence, treatment satisfaction and costs, in fixed-dose combination regimens in type 2 diabetes. Curr Med Res Opin 27: 1157-1168

63. Seedat YK (2008) Fixed drug combination in hypertension and hyperlipidaemia in the developing world. Cardiovasc J Afr 19: 124-126. [crossref]

\section{Citation:}

Mohammad Yaasir Ozeer, Manish Putteeraj and Jhoti Somanah Bhugowandeen (2019) The Need for Fixed Dose Combination (FDC) for the Management of Type 2 Diabetes in Mauritius. Endocrinol Diabetes Metab J Volume 3(3): 1-9. 